\title{
PENETAPAN KADAR RIBOFLAVIN, PIRIDOKSIN HCI, DAN ASAM FOLAT DALAM SUSU FORMULA BAYI DENGAN KROMATOGRAFI CAIR KINERJA TINGGI (KCKT)
}

\author{
Nurmahida Pagama, Yusnita Rifai dan Muhammad Aswad \\ Fakultas Farmasi, Universitas Hasanuddin, Makassar
}

Kata Kunci :

KCKT, susu formula, riboflavin, piridoksin $\mathrm{HCl}$, asam folat

\begin{abstract}
ABSTRAK
Susu formula bayi merupakan pengganti air susu ibu yang diproduksi untuk memenuhi kebutuhan gizi bayi selama bulan-bulan pertama kehidupannya hingga pengenalan makanan pelengkap yang sesuai. Riboflavin, piridoksin $\mathrm{HCl}$ dan asam folat diekstraksi dari susu formula bayi dengan dapar fosfat $\mathrm{pH} 4,5$ dan asetonitril yang telah diasamkan dengan asam fosfat. Kondisi kromatografi yang digunakan: kolom Atlantis C18 4.6 × $150 \mathrm{~mm} 5 \mu \mathrm{m}$, fase gerak terdiri dari dapar fosfat pH 4,5 dan campuran asetonitril dengan dapar fosfat $\mathrm{pH}$ 4,5 (7:3), menggunakan sistem kromatografi gradien dengan laju alir 0,5 $\mathrm{mL} /$ menit. Riboflavin diukur pada panjang gelombang $270 \mathrm{~nm}$, piridoksin $\mathrm{HCl} 290 \mathrm{~nm}$ dan asam folat $280 \mathrm{~nm}$. Dari hasil uji linieritas diperoleh nilai $r>0.999$ dan nilai VX0 kurang dari 5\% yaitu berkisar antara 2.28-2.79\%, dengan rentang konsentrasi larutan standar yaitu 0,05-10,00 $\mu \mathrm{g} / \mathrm{mL}$ untuk riboflavin, piridoksin $\mathrm{HCl} 0,03-2,00 \mu \mathrm{g} / \mathrm{mL}$ dan asam folat 0,01-2,00 $\mu \mathrm{g} / \mathrm{mL}$. Presisi yang disajikan dalam bentuk relative standard deviation (\%RSD) untuk analisa riboflavin, piridoksin $\mathrm{HCl}$ dan asam folat berturutturut adalah: 0,75; 3,60 dan 1,21\%. Hasil evaluasi menunjukkan kadar masing-masing 10,95 $\mu \mathrm{g} / \mathrm{g}$ untuk riboflavin, 3,97 $\mu \mathrm{g} / \mathrm{g}$ untuk piridoksin dan $0.96 \mu \mathrm{g} / \mathrm{g}$ untuk asam folat. Riboflavin, piridoksin $\mathrm{HCl}$ dan asam folat dapat ditetapkan kadarnya secara simultan dengan KCKT detektor UV pada kondisi analisis yang disebutkan.
\end{abstract}

\section{PENDAHULUAN}

Vitamin dibedakan menjadi senyawa larut air dan larut lemak. Riboflavin, piridoksin $\mathrm{HCl}$ dan asam folat termasuk vitamin larut air. Vitamin dibutuhkan oleh manusia dalam jumlah relatif kecil untuk membantu berbagai proses kehidupan dan kesehatan manusia. Tubuh manusia tidak dapat memproduksi vitamin oleh karena itu harus diperoleh dari luar baik bersumber dari makanan maupun minuman. Kebutuhan vitamin meningkat selama masa kehamilan, menyusui, dan masa pertumbuhan. Terkadang, kebiasaan makan bisa membuat kekurangan vitamin dan memicu beberapa penyakit kronis (1).

Piridoksin $\mathrm{HCl}$ diperlukan untuk sintesis neurotransmitter pada sistem syaraf (2). Folat berperan penting dalam sintesa beberapa jenis asam amino dan berbagai reaksi biosintesis, katabolik dan reaksi interkonversi dan sintesis pirimidin. Defisiensi folat pada ibu hamil dapat menyebabkan cacat lahir pada bayi, down syndrome, orofacial clefts dan congenital heart defects (3). Riboflavin penting untuk aktifasi vitamin B6 dan konversi triptofan ke niasin (4). Selain itu riboflavin juga bertidak sebagai koenzim dehidrogenasene dan esensial bagi metabolisme glukosa serta asam lemak (5).

Meskipun air susu ibu (ASI) merupakan sumber nutrisi bayi yang paling optimal, banyak orang tua menggunakan susu formula sebagai pengganti ASI. Susu formula bayi memiliki kandungan nutrisi lebih sedikit dibandingkan ASI termasuk berbagai jenis sel hidup, kolesterol, poliamina, asam amino bebas, enzim dan berbagai macam zat bioaktif lainnya (6).
Susu yang layak dikonsumsi oleh manusia melewati berbagai proses guna mencegah adanya bahaya terhadap kesehatan yang disebabkan oleh mikroorganisme patogen yang ada dalam susu mentah. Susu cair diproduksi melalui proses pemanasan seperti pasteurisasi ultra-heat treatment atau ultra-high temperature (UHT) dan sterilisasi. Sedangkan untuk membuat susu kering (serbuk), pertama susu dipanaskan kemudian dikeringkan melalui proses spray drying, rollerdrying, atau drum drying. Proses-proses ini akan merusak beberapa nutrisi terutama vitamin yang secara alami terdapat dalam susu (7). Oleh karena itu diperlukan suatu metode untuk menentukan kadar vitamin dalam susu formula (riboflavin, piridoksin, asam folat) guna memastikan asupan vitamin yang diperoleh dari susu formula sesuai untuk kebutuhan bayi. Metode ini harus sederhana dengan akurasi tinggi, reproducible, dan hasil yang stabil.

\section{METODE PENELITIAN}

\section{Alat dan Bahan Penelitian}

HPLC Shimadzu® LC 20 AD, kolom Atlantis® T3 C18 4.6 x $150 \mathrm{~mm} 5 \mu \mathrm{m}$, sistem pemurnian air ELGA PureLab Flex, Power Sonic 410, neraca mikro (Sartorius $\AA$ ), neraca analitik (Sartorius $®$ ), pH Meter (Mettler Toledo®), Multi-tube Carrier Refrigerated Centrifuge, vortex, pipet Eppendorf dan alat- alat gelas.

Standar vitamin riboflavin BPFI, piridoksin $\mathrm{HCl}$ BPFI dan asam folat BPFI (diperoleh dari laboratorium baku pembanding PPPOMN), 
asetonitril gradient grade for Liquid Chromatography (Merck), metanol gradient grade for Liquid Chromatography (Merck), kalium dihidrogen fosfat (Merck), natrium hidroksida (Merck), asam fosfat $85 \%$ (Merck), asam asetat glasial (Merck), susu formula bayi dalam bentuk serbuk dengan kemasan dus, membrane filter $0,45 \mu \mathrm{m}$, syringe filter $0,45 \mu \mathrm{m}$, kertas saring Agilent PTFE $0,45 \mu \mathrm{m}$.

\section{Prosedur Penelitian}

\section{Kondisi Analisis}

Pada penelitian ini digunakan KCKT detektor UV dengan sistem elusi gradien di mana komposisi fase gerak berubah selama proses pengukuran berlangsung. Fase gerak yang digunakan adalah dapar fosfat $10 \mathrm{mM}$ pH 4,5 (A) dan campuran dapar fosfat : asetonitril, 7:3 (B). Sebagai fase diam digunakan kolom Atlantis T3 C18 (4,6 mm x $150 \mathrm{~mm}), 5 \mu \mathrm{m}$. Suhu oven $35^{\circ} \mathrm{C}$, dengan laju alir $0,5 \mathrm{~mL} /$ menit dan volume penyuntikan $20 \mu \mathrm{L}$. Detektor UV diset pada panjang gelombang $290 \mathrm{~nm}$ untuk pengukuran piridoksin $\mathrm{HCl}, 280$ untuk asam folat dan $270 \mathrm{~nm}$ untuk riboflavin.

\section{Uji Kesesuaian Sistem}

Larutan baku riboflavin dengan konsentrasi $2 \mu \mathrm{g} / \mathrm{mL}$ piridoksin $\mathrm{HCl} 0,4 \mu \mathrm{g} / \mathrm{mL}$, dan asam folat $0,4 \mu \mathrm{g} / \mathrm{mL}$ disuntikkan ke KCKT sebanyak $20 \mu \mathrm{L}$ pada kondisi analisa yang sesuai. Penyuntikan diulang minimal 5 kali. Jumlah lempeng teoritis, faktor kapasitas, resolusi, faktor ikutan (tailing factor), dan standar deviasi relatif luas area puncak dan waktu retensi dihitung untuk mengetahui apakah uji kesesuaian sistem memenuhi syarat.

\section{Linearitas}

Larutan baku kerja riboflavin dibuat dengan konsentrasi 0,$0504 ; 0,1259 ; 0,2518 ; 0,5036 ; 1,0071 ; 2,0142 ; 4,0284$ 8,0569 dan $10,0711 \mu \mathrm{g} / \mathrm{mL}$. Larutan baku kerja piridoksin $\mathrm{HCl}$ dibuat dengan konsentrasi 0,$0126 ; 0,0315 ; 0,0629$; 0,$1259 ; 0,2518 ; 0,5035 ; 1,0070 ; 2,0141$ dan $2,5176 \mu \mathrm{g} / \mathrm{mL}$. Larutan baku kerja asam folat dibuat dengan konsentrasi 0,$0108 ; 0,0269 ; 0,0538 ; 0,1075 ; 0,2151 ; 0,4302 ; 0,8603$; 1,7207 dan 2,1508 $\mu \mathrm{g} / \mathrm{mL}$. Larutan baku kemudian disuntikkan sebanyak $20 \mu \mathrm{L}$ ke KCKT. Dari hasil analisa yang diperoleh, kemudian dibuat perbandingan antara luas area (y) terhadap konsentrasi riboflavin, piridoksin $\mathrm{HCl}$, dan asam folat (x). Koefisien korelasi (r) dihitung dari persamaan garis regresi linier tersebut dan juga nilai VX0.

\section{Presisi}

Sampel susu dihomogenkan dan ditimbang sebanyak $6 \mathrm{~g}$ kemudian dimasukkan ke dalam labu propilen $50 \mathrm{~mL}$. Larutan dapar fosfat pH 4,5 ditambahkan sebanyak $20 \mathrm{~mL}$, divorteks selama 15 menit. Asetonitril yang telah diasamkan dengan $20 \mu \mathrm{L}$ asam fosfat $85 \%$ ditambahkan sebanyak $20 \mathrm{~mL}$, dihomogenkan dengan vortex selama 3 menit. Dilakukan sentrifugasi dengan kecepatan 2500 rpm selama 30 menit. Filtrat diambil sebanyak $10 \mathrm{~mL}$, dimasukkan ke dalam tabung reaksi. Dikeringkan hingga kurang lebih $1 \mathrm{~mL}$ dengan menggunakan nitrogen evaporator. Dipindahkan ke labu takar amber $10 \mathrm{~mL}$, volumenya dicukupkan hingga tanda dengan dapar fosfat $\mathrm{pH} 4,5$. Larutan dihomogenkan dengan vorteks selama 1 menit. Larutan disaring dengan membrane filter $0,45 \mu \mathrm{m}$ ke dalam vial amber $2 \mathrm{~mL}$ dan diawaudarakan selama 5 menit. Diinjekkan ke KCKT sebanyak $20 \mu \mathrm{L}$. Dilakukan minimal enam (6) kali pengerjaan sampel yang sama untuk menentukan presisi.

\section{Akurasi}

Sampel susu yang telah dihomogenkan ditimbang sebanyak 6 $\mathrm{g}$ dan di masukkan ke dalam labu propilen $50 \mathrm{~mL}$. Ditambahkan standar riboflavin piridoksin dan asam folat.
Larutan dapar fosfat $\mathrm{pH}$ 4,5 ditambahkan sebanyak $20 \mathrm{~mL}$, divorteks selama 15 menit.

Asetonitril yang telah diasamkan dengan $20 \mu \mathrm{L}$ asam fosfat 85\% ditambahkan sebanyak $20 \mathrm{~mL}$, dihomogenkan dengan vortex selama 3 menit. Dilakukan sentrifugasi dengan kecepatan $2500 \mathrm{rpm}$ selama 30 menit. Filtrat diambil sebanyak $10 \mathrm{~mL}$, dimasukkan ke dalam tabung reaksi amber. Dikeringkan hingga kurang lebih $1 \mathrm{~mL}$ dengan menggunakan nitrogen evaporator. Dipindahkan ke labu amber $10 \mathrm{~mL}$, volumenya dicukupkan hingga tanda dengan dapar fosfat $\mathrm{pH}$ 4,5. Larutan dihomogenkan dengan vortex selama 1 menit. Larutan disaring dengan membrane filter $0,45 \mu \mathrm{m}$ ke dalam vial amber $2 \mathrm{~mL}$ dan diawaudarakan selama 5 menit. Diinjekkan ke KCKT sebanyak $20 \mu \mathrm{L}$. Dilakukan tiga (3) kali replikasi pengerjaan sampel yang sama untuk menentukan akurasi.

\section{HASIL DAN PEMBAHASAN}

Pada penelitian ini, optimasi penetapan kadar riboflavin, piridoksin $\mathrm{HCl}$ dan asam folat meliputi penentuan fase gerak dan laju alir serta metode ekstraksi analit dari susu formula. Sistem elusi yang digunakan adalah sistem gradien di mana komposisi fase gerak berubah selama proses pengukuran berlangsung. Kolom yang digunakan adalah kolom reversedphase Atlantis T3 C18 dengan dimensi 4,6 mm x $150 \mathrm{~mm}$, diameter partikel 0,5 $\mu \mathrm{m}$. Kecepatan alir 0,5 mL/menit, suhu oven $35{ }^{\circ} \mathrm{C}$ dengan volume penyuntikan $20 \mu \mathrm{L}$. Sebagai fase gerak, digunakan dapar fosfat $\mathrm{pH} 4,5$ dan campuran pelarut asetonitril : dapar fosfat pH 4,5 (7:3). Detektor diset pada panjang gelombang $270 \mathrm{~nm}$ untuk penukuran riboflavin, 280 $\mathrm{nm}$ untuk asam folat dan $290 \mathrm{~nm}$ untuk piridoksin $\mathrm{HCl}$.

Fase gerak dibuat segar untuk menjamin pH larutan dapar tidak berubah juga tidak ada pertumbuhan mikroba. Pelarut dan pereaksi harus berkualitas tinggi untuk mencegah terjadinya puncak-puncak palsu pada baseline kromatogram sehingga menyulitkan pengukuran. Fase gerak harus disaring terlebih dahulu sebelum digunakan dengan penyaring membran 0,45 $\mu \mathrm{m}$ dan disonikasi untuk menghilangkan gas yang terdapat di dalamnya untuk menghindari berkumpulnya gas pada pompa dan detektor yang dapat mengacaukan analisis. UV cut off pelarut organik dan dapar harus diperhatikan khususnya saat melakukan analisis pada panjang gelombang di bawah $200 \mathrm{~nm}$. Gangguan ultraviolet dari dapar dan pelarut organik akan mengurangi sensitifitas detektor yang akan menyebabkan gangguan pada baseline.

Sistem KCKT harus diuji terlebih dahulu sebelum digunakan melalui uji kesesuaian sistem untuk menjamin bahwa sistem operasional KCKT memberikan hasil yang sesuai untuk tujuan analisis. Hal ini dikarenakan banyak faktor yang dapat memberikan perbedaan hasil uji seperti jenis kolom, umur kolom, komposisi dan $\mathrm{pH}$ fase gerak. Uji kesesuaian sistem dilakukan minimal 5 kali penyuntikan.

\begin{tabular}{ccccccc}
\hline \multirow{6}{*}{ Tabel 1. Hasil uji rata-rata kesesuaian sistem analisis } \\
\hline \multicolumn{5}{c}{ Rata-Rata Nilai } \\
\cline { 2 - 7 } & $\mathbf{N}$ & Rs & T & $\begin{array}{c}\text { RSD Area } \\
\text { (\%) }\end{array}$ & $\mathbf{k}^{\prime}$ \\
\hline Riboflavin & 141845,879 & 16,568 & 1,265 & 0,386 & 1,491 \\
Piridoksin HCl & 7922,316 & 0,000 & 1,293 & 0,164 & 0,000 \\
Asam Folat & 113707,526 & 30,762 & 1,344 & 0,854 & 1,069 \\
\hline Syarat & $\geq \mathbf{2 0 0 0}$ & $\geq \mathbf{1 , 5}$ & $\leq \mathbf{1 , 5}$ & $<\mathbf{2 , 0}$ & $\mathbf{1}$ - 10 \\
\hline
\end{tabular}

Keterangan: $\mathrm{N}=$ Jumlah lempeng teoritis; $\mathrm{T}=$ Faktor ikutan; Rs= Resolusi; RSD= Relative percent difference; $k^{\prime}=$ faktor kapasitas 


\begin{tabular}{ccc}
\multicolumn{3}{l}{ Tabel 2. Pengukuran linieritas riboflavin } \\
\hline No. & Kadar $(\mu \mathrm{g} / \mathrm{mL})$ & Area $(\mathrm{uV})$ \\
\hline 1. & 0,050355 & 6842 \\
2. & 0,125889 & 13192 \\
3. & 0,251777 & 26366 \\
4. & 0,503554 & 48147 \\
5. & 1,007109 & 87185 \\
6. & 2,014218 & 241834 \\
7. & 4,028436 & 473190 \\
8. & 8,056873 & 900540 \\
9. & 10,071091 & 1176723 \\
\hline
\end{tabular}

$\mathrm{Y}=115767,4414 \mathrm{X}-5398,7068 ; \mathrm{r}$ hitung $=0,999339, \mathrm{Vxo}=2,79 \%$

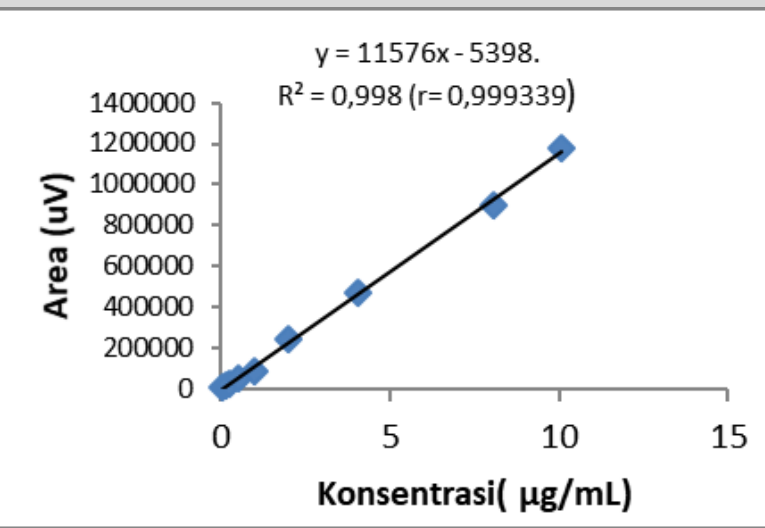

Gambar 1. Kurva linieritas standar riboflavin.

Tabel 3. Hasil uji linieritas piridoksin $\mathrm{HCl}$

\begin{tabular}{ccc}
\hline No. & Kadar $(\mu \mathrm{g} / \mathrm{mL})$ & Area $(\mathrm{uV})$ \\
\hline 1. & 0,031470 & 1615 \\
2. & 0,062941 & 3275 \\
3. & 0,125882 & 6138 \\
4. & 0,251764 & 13034 \\
5. & 0,503527 & 33902 \\
6. & 1,007055 & 67053 \\
7. & 2,014110 & 129818 \\
8. & 2,517637 & 169374 \\
\hline
\end{tabular}

$Y=66957,57311 X-1497,3111 ; r$ hitung $=0,999493, V \times o=2,28 \%$

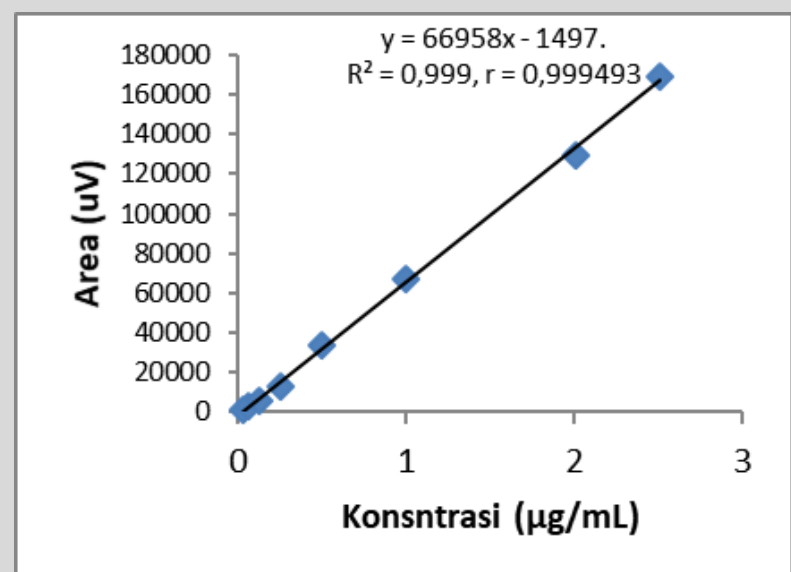

Gambar 2. Kurva linieritas standar Piridoksin $\mathrm{HCl}$

\begin{tabular}{ccc}
\multicolumn{3}{l}{ Tabel 4. Hasil uji linieritas asam folat } \\
\hline No. & Kadar $(\boldsymbol{\mu g} / \mathrm{mL})$ & Area $(\mathrm{uV})$ \\
\hline 1. & 0,010754 & 1754 \\
2. & 0,026886 & 3379 \\
3. & 0,053771 & 7009 \\
4. & 0,107543 & 12321 \\
5. & 0,215086 & 24309 \\
6. & 0,430171 & 67528 \\
7. & 0,860343 & 132287 \\
8. & 1.720686 & 253130 \\
9 & 2,150857 & 329797 \\
\hline
\end{tabular}

\section{$Y=152301,4683 X-1970,2974 ; r$ hitung $=0,999389, V \times o=2,68 \%$}

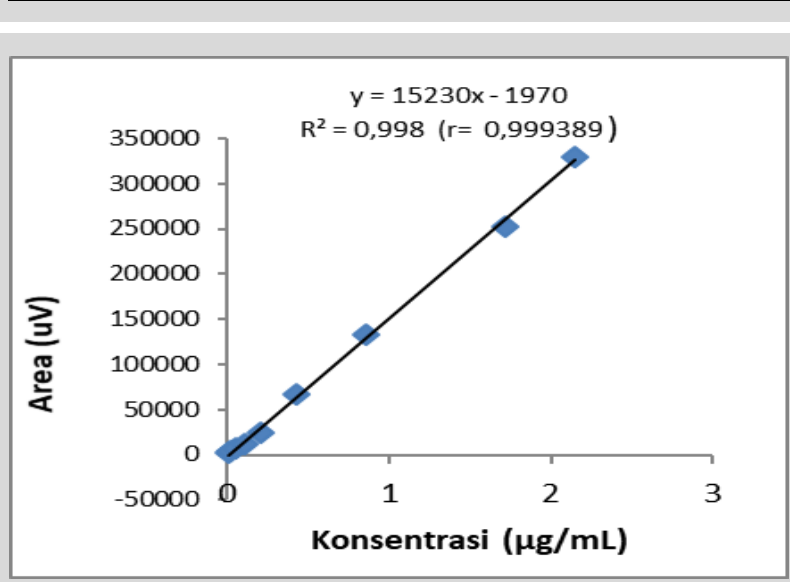

Gambar 3. Kurva linieritas standar asam folat.

Penetapan linieritas dilakukan untuk melihat apakah metode analisa dapat memberikan respon yang proporsional terhadap konsentrasi analit dalam sampel. Dilakukan penentuan linieritas dengan 9 konsentrasi berbeda, yaitu standar riboflavin dengan konsentrasi $0,05-10,00 \mu \mathrm{g} / \mathrm{mL}$, piridoksin $\mathrm{HCl} 0,03-2,00 \mu \mathrm{g} / \mathrm{mL}$ dan asam folat konsentrasi 0,01-2,00 $\mu \mathrm{g} / \mathrm{mL}$. Linieritas dikatakan baik jika koefisien determinasi (R2) >0,997 atau $r>0,999$ dengan nilai $\mathrm{Vx} 0$ sebagai parameter lain dari linieritas harus kurang dari $5 \%$ (8).

\begin{tabular}{ccc}
\multicolumn{3}{c}{ Tabel 5. Hasil uji presisi riboflavin } \\
\hline No. & Area (uV) & Kadar $(\boldsymbol{\mu g} / \mathbf{g}))$ \\
\hline 1 & 186026 & 10,9948 \\
2 & 184917 & 10,9582 \\
3 & 184617 & 10,9418 \\
4 & 186649 & 11,0482 \\
5 & 185574 & 10,9818 \\
6 & 182497 & 10,8034 \\
\hline & Rata-rata & $\mathbf{1 0 , 9 5 4 7}$ \\
& Standar deviasi & $\mathbf{0 , 0 8 2 6}$ \\
& RSD (\%) & $\mathbf{0 , 7 5}$ \\
& Syarat (RSD Horwitz) & $\mathbf{7 , 4 4}$ \\
\hline
\end{tabular}

Kemudian dilakukan uji presisi dengan 6 replikasi di mana kriteria penerimaan RSD lebih kecil dari $2 / 3$ x CV Horwitz. CV Horwitz $=21-0,5 \log \mathrm{C}$, di mana $\mathrm{c}$ adalah fraksi konsentrasi. Presisi merupakan ukuran keterulangan metode analisis dan biasanya diekspresikan sebagai simpangan baku relatif (RSD) (Gandjar dan Rohman, 2014). Dari hasil perhitungan diperoleh kadar riboflavin 10,96 $\mu \mathrm{g} / \mathrm{g}$, piridoksin $\mathrm{HCl} 3,97$ $\mu \mathrm{g} / \mathrm{g}$ dan asam folat $0.96 \mu \mathrm{g} / \mathrm{g}$ dengan nilai RSD masing 
masing 0,75\% untuk riboflavin, 3,60\% untuk piridoksin $\mathrm{HCl}$ dan $1,21 \%$ untuk asam folat.

\begin{tabular}{|c|c|c|}
\hline No. & Area (uV) & Kadar $(\mu \mathrm{g} / \mathrm{g}))$ \\
\hline 1 & 39220 & 4,0435 \\
\hline 2 & 39450 & 4,0764 \\
\hline 3 & 37626 & 3,8951 \\
\hline 4 & 37453 & 3,8742 \\
\hline 5 & 36419 & 3,7698 \\
\hline 6 & 40192 & 4,1443 \\
\hline \multicolumn{2}{|c|}{ Rata-rata } & 3,9672 \\
\hline \multicolumn{2}{|c|}{ Standar deviasi } & 0,1428 \\
\hline \multicolumn{2}{|c|}{ RSD (\%) } & 3,60 \\
\hline \multicolumn{2}{|c|}{ Syarat (RSD Horwitz) } & 8,67 \\
\hline \multicolumn{3}{|c|}{ Tabel 7. Hasil uji presisi asam folat } \\
\hline No. & Area (uV) & Kadar ( $\mu \mathrm{g} / \mathrm{g})$ \\
\hline 1 & 19737 & 0,9477 \\
\hline 2 & 19897 & 0,9571 \\
\hline 3 & 20030 & 0,9630 \\
\hline 4 & 20234 & 0,9710 \\
\hline 5 & 20081 & 0,9639 \\
\hline 6 & 20494 & 0,9818 \\
\hline \multicolumn{2}{|c|}{ Rata-rata } & 0,9641 \\
\hline \multicolumn{2}{|c|}{ Standar deviasi } & 0,0117 \\
\hline \multicolumn{2}{|c|}{ RSD (\%) } & 1,21 \\
\hline \multicolumn{2}{|c|}{ Syarat (RSD Horwitz) } & 10,72 \\
\hline
\end{tabular}

Selanjutnya dilakukan penentuan akurasi untuk mengetahui kedekatan antara nilai terukur dengan nilai sebenarnya yang ditunjukkan dengan persen perolehan kembali (\%recovery). Akurasi diukur dengan menambahkan analit pada tiga (3) konsentrasi yang berbeda, masing-masing tiga replikasi. Berdasarkan hasil perhitungan yang diperoleh, akurasi piridoksin dan asam folat memenuhi syarat yang ditetapkan yaitu $80-110 \%$. Akurasi riboflavin pada penambahan standar riboflavin 3,8955 $\mu \mathrm{g}$ tidak memenuhi syarat. Hal ini kemungkinan disebabkan karena kadar riboflavin pada penambahan standar riboflavin 3,8955 $\mu \mathrm{g}$ telah melewati limit pembacaan detektor. Kemungkinan yang lain adalah

\begin{tabular}{|c|c|c|c|}
\hline $\begin{array}{c}\Sigma \text { Riboflavin yang } \\
\text { ditambahkan } \\
(\mu \mathrm{g})\end{array}$ & $\begin{array}{c}\text { Replikasi } \\
\text { ke- }\end{array}$ & $\begin{array}{l}\text { Perolehan } \\
\text { kembali (\%) }\end{array}$ & $\begin{array}{c}\text { Syarat } \\
\text { perolehan } \\
\text { kembali (\%) }\end{array}$ \\
\hline \multirow{3}{*}{2,6969} & 1 & 95,39 & \multirow{3}{*}{$80-110$} \\
\hline & 2 & 108,46 & \\
\hline & 3 & 94,40 & \\
\hline \multirow{3}{*}{3,2588} & 1 & 90,82 & \multirow{3}{*}{$80-110$} \\
\hline & 2 & 100,40 & \\
\hline & 3 & 90,74 & \\
\hline \multirow{3}{*}{3,8955} & 1 & - & \multirow{3}{*}{$80-110$} \\
\hline & 2 & - & \\
\hline & 3 & - & \\
\hline
\end{tabular}

adanya analit riboflavin yang hilang selama proses preparasi dan proses pemisahan riboflavin dari komponen-komponen lain yang ada dalam susu yang tidak sempurna.

\begin{tabular}{|c|c|c|c|}
\hline $\begin{array}{c}\Sigma \text { Piridoksin } \mathrm{HCl} \\
\text { yang } \\
\text { ditambahkan } \\
(\mu \mathrm{g})\end{array}$ & $\begin{array}{l}\text { Replikasi } \\
\text { ke- }\end{array}$ & $\begin{array}{c}\text { Perolehan } \\
\text { kembali (\%) }\end{array}$ & $\begin{array}{c}\text { Syarat } \\
\text { perolehan } \\
\text { kembali (\%) }\end{array}$ \\
\hline \multirow{3}{*}{0,9526} & 1 & 89,61 & \multirow{3}{*}{$80-110$} \\
\hline & 2 & 87,68 & \\
\hline & 3 & 108,67 & \\
\hline \multirow{3}{*}{1,0825} & 1 & 85,80 & \multirow{3}{*}{$80-110$} \\
\hline & 2 & 83,22 & \\
\hline & 3 & 89,78 & \\
\hline \multirow{3}{*}{1,4290} & 1 & 95,03 & \multirow{3}{*}{$80-110$} \\
\hline & 2 & 98,73 & \\
\hline & 3 & 101,45 & \\
\hline
\end{tabular}

\begin{tabular}{|c|c|c|c|}
\hline $\begin{array}{c}\text { ¿ Asam Folat yang } \\
\text { ditambahkan } \\
(\mu \mathrm{g})\end{array}$ & $\begin{array}{l}\text { Replikasi } \\
\text { ke- }\end{array}$ & $\begin{array}{c}\text { Perolehan } \\
\text { kembali (\%) }\end{array}$ & $\begin{array}{c}\text { Syarat } \\
\text { perolehan } \\
\text { kembali (\%) }\end{array}$ \\
\hline \multirow{3}{*}{0,9526} & 1 & 89,61 & \multirow{3}{*}{$80-110$} \\
\hline & 2 & 87,68 & \\
\hline & 3 & 108,67 & \\
\hline \multirow{3}{*}{1,0825} & 1 & 85,80 & \multirow{3}{*}{$80-110$} \\
\hline & 2 & 83,22 & \\
\hline & 3 & 89,78 & \\
\hline \multirow{3}{*}{1,4290} & 1 & 95,03 & \multirow{3}{*}{$80-110$} \\
\hline & 2 & 98,73 & \\
\hline & 3 & 101,45 & \\
\hline
\end{tabular}

\section{KESIMPULAN}

Berdasarkan penelitian yang telah dilakukan dapat disimpulan bahwa kadar riboflavin, piridoksin dan asam folat dalam susu formula bayi dapat ditentukan secara simultan dengan KCKT detektor UV sedangkan riboflavin tidak

\section{DAFTAR PUSTAKA}

1. Maria Katsa; Charalampos Proestos; Efstratios Komaitis. 2016. Determinations of fat soluble vitamins. 92-96.

2. Dakshinamurti, S.; Dakshinamurti, K. 2007. Vitamin B6, In Handbook of vitamins, Fourth ed.; Zempleni, J., Rucker, R. B. and McCormick D. B., S.J.W., Eds.; CRC Press: Boca Raton. p. 315.

3. Hobbs, C. A.; Shaw, G. M.; Werler, M. M.; Mosley, B. 2010. Folate status and birth defect risk. Epidemiological perspective. In L. B. Bailey (Ed.), Folate in Health and Disease, (2nd edition). Boca Raton, Forida, USA: CRC Press (Taylor \& Francis Group, LLC). pp. 133-153.

4. Navarra, T. 2004. The encyclopedia of vitamins, minerals and supplements. Facts On File, Inc: New York, NY.

5. György, P. 2008. Riboflavin, In The vitamins: fundamental aspects in nutrition and health. Third ed.; Combs, G.F., Ed.; Elsevier Academic Press. Boston. p. 281.

6. O'Connor, MD. 2009. Infant Formula. American Family Physician. Volume 79, Number 7, p. 565.

7. USAID. Fortification Basic.

8. Yuwono, M., Indrayanto, G., 2005. Validation of chromatographic method of analysis. Profiles of drug subtances, excipients, and elated Methodology, Vol. 32, p. 243-259. 